by comparing our individual experience we shall best arrive at just clinical and pathological conclusions.

Dr. Radcliffe Crocker, President of the Section, insisted on the importance of drawing attention to forms of dermatitis due to disease of the internal organs. In his experience he differed from Dr. Pye-Smith as to prognosis, which was gloomy in advanced cases of Bright's disease. He agreed with Dr. Le Cronier Lancaster.

Dr. SAvill (London), referring to the exfoliative skin diseases mentioned by Dr. Pye-Smith, said that his subsequent experience of the epidemic skin disease led him to believe that renal disease formed a predisposition to contract the former. Out of five or six cases of such complication which he had seen, all were fatal. He regarded it as a very serious sign.

Dr. Bradbury (Cambridge) had seen several cases of skin diseases occurring towards the end of morbus Brightii. He had observed erythemata, and one case was markedly urticarial. In cases of interstitial nephritis he thought the element gout, plus poisonous matter retained in the blood through imperfect elimination by the kidneys, might be a factor. He admitted this did not explain all cases, especially those of chronic tubal nephritis. He was of opinion that the prognosis in these cases was unfavourable-that the end was not far distant.

Dr. WALDO (Clifton) asked Dr. Pye-Smith whether he had often noticed that the serum after blistering cases of chronic Bright's disease was hæmorrhagic.

Dr. GraNGe had noticed urticaria.

In his reply, Dr. Pre.Smrth did not think there was any evidence of uræmic origin; he had never seen skin affections in very bad cases of Bright's disease. Eruptions did not give him that grave augury as to prognosis which had been mentioned by other speakers. He had never noticed urticaria as seen by Dr. Grange. He was extremely sceptical as to the influence of gout. In reply to Dr. Waldo, he had had no experience of blistering leading to hæmorrhagic serum; in this respect he would point out that in Bright's disease one should never give opium or mercury, or apply a blister.

\section{ON THE GUINEA-WORM.}

By PATRICK MANSON, M.D.ABerd., F.R.C.P.LOND., ETC., Physician to the Seamen's Hospital, Greenwich.

WHEN mature this singular integumental parasite-dracunculus medinensis or guinea-worm, of which the female form alone is known, attains an enormous length $-2,3$, or 4 feet. Though long, she is very slender, having a diameter of about the tenth of an inch. Her anatomy is very simple; practically she may be described as a musculo-cutaneous tube, enclosing an exceedingly delicate uterus, which, packed with millions of coiled up, long-tailed embryos, extends from mouth to tail The head of the adult worm is rounded off, and is provided with a punctiform mouth and a crown of minute papillæ; the tail end is furnished with a sort of hook which possibly functions as a holdfast. The alimentary canal is a minute tube compressed and thrust to one side by the uterus. Vagina and anus are wanting - at all events they have not been seen ; probably they are obliterated by the pressure of the enormous uterus.

When the embryos in her uterus attain a certain degree of maturity, the worm travels slowly through the connective tissues of her host, proceeding almost invariably in a downward direction towards the lower extremities. She generally gets as far as the ankle or foot. Arrived there she drills a minute hole in the derma, the superjacent epidermis being raised up as a bleb. In a day or two the bleb bursts or is broken, disclosing a superficial ulcer with the little hole, leading to, or, more rarely, occupied by, the head of the parasite, at its centre.

The prevailing idea is that the worm now creeps out, or is pulled out, and that her body, being cast away, decomposes, and so liberates the embryos. Another idea is that the worm breaking down in the tissues, her young escapes in the purulent discharge which the irritation of her presence excites. It

1 Read in the Section of Dermatology at the Annual Meeting of the British Medical Association held in London, July-August, 1895 can easily be shown, however, that neither of these views is correct. The worm gives rise to no purulent discharge so long as she is alive; nor, left alone, does she quit the body until she has first got rid of her young. This can be shown by the following experiment :

Squeeze a little cold water from a sponge so that the stream shall fall on the sound skin within an inch or two of a guinea. worm ulcer; at the same time watch the little hole alluded to at the centre of the ulcer. In a few seconds a droplet of a whitish fluid will be seen to well up in the little hole, or a delicate tube will be protruded from it for an inch or more, and then suddenly rupture. Collect a little of the fluid that has welled up from the hole or escaped from the ruptured tube, and place it under the microscope. It will be seen to contain hundreds of coiled-up, apparently dead, embryo guinea-worms. Instil a little water below the cover-glass and watch. In a few minutes the embryos seem to wake up, stretch themselves, move, and in a very short time they are swimming about vigorously. Manifestly they are in their proper element--water.

The explanation of these facts, which I have frequently witnessed and shown to others, is this. The parent guineaworm instinctively makes her way to the foot or ankle because her young are most likely to get to water in that situation. In guinea-worm countries the natives wear neither shoes nor stockings, and their feet especially are frequently in puddles of water. In some strange way the guinea-worm recognises this fact, and also recognises when the foot of her host is actually in contact with the water. So she makes her way to the foot or ankle, and at the right moment, when the foot touches water, expels her young just as when we experimentally douche the limb she is lying in. I find she takes about a fortnight to empty her uterus in such inter. mittent efforts at parturition. When all her young have been expelled she begins to come out herself, and can then be more or less readily withdrawn, or she may break down and excite suppuration. I may mention that as the parasite has no vagina she gets rid of her young through her mouth; the contractions of the musculo-cutaneous wall, in response to the stimulus of water applied to the skin of her host, cause the uterus to prolapse through the mouth and burst. An inch or two of uterus prolapses each time the stimulus is applied; becoming very tense under the sustained contractions of the body of the worm, it ruptures and shrivels up and so on until the entire organ is in time expelled.

The object of all these curious arrangements is to give the guinea-worm embryo the best possible chance to get at its intermediate host-a fresh water crustacean, cyclops quadricornis. Fedschenko, now a good many years ago, discovered that cyclops was the intermediate host of the dracunculus, and convinced Leuckart and other helminthologists of this. But, so far as I know, his experiments had not been confirmed or repeated until last year. Having a case of guinea-worm under my care at the Seamen's Hospital, I bethought me of testing Fedschenko's statements, and also of seeing if the guinea-worm could be raised in England. I procured a large. supply of embryos by the douching process I have described, and placed them in watch glasses and little bottles, together with a number of cyclops collected from ponds in the neighbourhood of London. They were placed together one evening. On the following morning, on looking at my cyclops with the microscope, I found that nearly every one of them had some ten or twenty guinea-worm embryos coiled up and wriggling about in their body cavities. The parasite had penetrated the armour of the cyclops by attacking it between the joints of the ventral plates; it does not get to the body cavity through the alimentary canal after being swallowed. I kept the cyclops alive for many weeks, and watched the slow metamorphosis of the incarcerated embryos. I repeated the experiment with the same success this year, as the preparations (for most of which I am indebted to Mr. Rousselet) and Mr. Andrew Pringle's very telling photographs show.

In this last set of experiments the parasites and the crustaceans were placed together on May 10th. I dissected, or rather crushed, a few cyclops from time to time, and so could follow the metamorphosis step by step. I found that soon after it enters cyclops the young guinea-worm changes its shape. When a free swimming animal the little embryos body is flattened from side to side, something like a very 
much elongated flounder. Soon after its entry into cyclops this flattened body becomes cylindrical. The embryo then, after a very variable time, casts its transversely.striated skin, and, along with this skin, gets rid of its long slender swimming tail, a short, conically-shaped, pointed tail, sometimes a mere rounded stump, taking its place. Apparently Fedschenko overlooked the cylindrification of the embryo and the formation of this conical tail. Later the parasite moults at least once again, the short conical tail giving place to a sort of tripartite caudal arrangement, something like a minute three-toothed trephine. Simultaneously with the changes described the young worm increases in size, its alimentary canal undergoing considerable development and becoming filled posteriorly with a brown granular material.

It is to be presumed that when this metamorphosis is completed the parasite is ready for transference to a human host by being swallowed in drinking water and while still in cyclops, and that under favourable circumstances it would attain maturity after boring its way into the connective tissues of its new human host.

I saw the metamorphosed guinea-worms alive and moving about in cyclops on July 19th, that is seventy days after their introduction. Fedschenko found that in the warmer climate of Turkestan thirty-five days sufficed for the metamorphosis. It takes longer in England therefore.

These are interesting biological facts. At the same time, they have one or two obvious practical bearings on the prevention and treatment of guinea-worm disease. First they show how desirable it is to abstain from unfiltered or unboiled drinking water in guinea-worm countries. They also indicate that it is wrong to commence winding out a guineaworm before she has expelled all her young, premature attempts at winding out being unphysiological, and sure, or nearly so, to end in rupture of the worm and the extravasation of myriads of young into the tissues, with consequent cellulitis and extensive sloughing. Though I unhesitatingly condemn premature attempts at winding out, I am inclined to think that the recently-recommended treatment of guineaworm by local injections of weak perchloride of mercury solution, with the view of killing the worm and procuring her absorption under aseptic conditions, is worth a trial.

Dr. Harrison (Clifton) asked Dr. Manson whether it were possible for a mass of guinea-worms to get encysted in the pleural cavity of a rhea, or American ostrich, as he had found a large cyst containing thirty or forty worms certainly closely resembling guinea worms in that animal about two years ago.

Dr. MANson said, in reply, that in dogs and many other animals various forms of filaria and other worms had been met with in the pulmonary vessels. The guinea-worm was known to occur in very many of the lower animals-dogs, horses, etc.-but he was not certain whether it had been found in the lungs.

\section{A DISCUSSION ON DIET IN THE ETIOLOGY AND TREATMENT OF DISEASES OF THE SKIN. ${ }^{1}$}

I.-W. Allan Jamieson, M.D., F.R.C P.Edin., Physician for Diseases of the Skin, Edinburgh Royal Infirmary, etc. IT appears to me that the object to be attained by discussions on particular and selected subjects at such a meeting as this is to elicit from those present facts which have come under their own observation bearing on the question to be considered. It is in this way, and in this way only, that the sum of our information can be by such means augmented. To pave the way to this end the member appointed to open the debate ought to lay down shortly the state of our knowledge on the matter at issue, and so to suggest to the minds of his audience lacunæ which one or other may be in a position more or less completely to fill up. Looked at in this light the topic with which we have to deal at present is: Diet in the Etiology and Treatment of Diseases of the Skin. It thus divides itself quite naturally into two heads intimately related to each other.

In the Section of Dermatology at the Annual Meeting of the British Medical Association, held in London, July-August, 1895.
First, then, with respect to the influence of food, taking the word in its widest sense, in causing or maintaining cutaneous disorders. There are at the outset certain limitations which narrow our field of observation. One of these is the relative frequency with which the ailment occurs. It is evident that in the case of uncommon complaints their very rarity acts as a barrier to exact inquiry. It is not possible to collect a sufficient number of instances to enable us to arrive at any definite conclusions on a matter which is in itself one of great difficulty. Again, many parasitic diseases are so far local disorders that the effect of diet in modifying the soil may be inconsiderable. There are diseases, too, of a chronic nature, such as scleroderma or fibroma, with respect to which we possess so far no available information; or acute maladies, as herpes zoster or ery thema iris, in which there is hardly any opportunity afforded for due estimation. There remain, however, after eliminating those not yet accessible, some with regard to which it may be possible to reach something positive. Such are, of the affections met with in this country, eczema. assuming this to mean broadly a catarrhal process, hyperidrosis, acne, dermatitis herpetiformis, lichen, lupus, epithelioma, and sarcoma. Unfortunately the data at disposal, even bearing on these diseases, are meagre, and to a considerable extent unreliable. We must reject in large measure the statements volunteered by our patients, though we thereby get much information. The former are vitiated by preconceived impressions, or are based on ill-founded deductions; the latter are necessarily imperfect. The patient in nearly all cases ascribes an immediate effect to his diet, though it may be obvious on the least reflection that the action, if exerted at all, must be remote. It is very perplexing, too, to allot the proper share to the individual constituents of a mixed dietary, in which there is no one largely preponderating and constant element, or any essential component markedly defective. The environment, too, of the individual has a relation to digestion which is in many instances beyond the power of our appraisement. The habits of the man as to regularity of ingestion or the reverse, come extensively into play in promoting or interfering with nutrition, and these may be unknown to or concealed from us.

Some articles of food act in producing cutaneous disorders in an immediate manner by the exertion of what may be termed a toxic or dynamic influence. Of this result urticaria is perhans the best example. but here idiosyncrasy comes into operation, since no one ingredient is capable of evoking wheals in all persons, or at all times even in the same person. Once initiated, however, the morbid tendency is apt to persist long after the original exciting cause must have ceased to be efficient. In such cases some ferment may cling to the intestinal walls, and continue for an indefinite period to exert its action on the products of digestion as they descend. This forms a link in the chain connecting this class with the next, in which the instrumentality of diet is a remote one. Much more frequently the influence of diet in provoking skin disease is to be attributed to slow and long-continued malassimilation. It is thus rather predisposing, the determining cause coming from without or depending on some accidental circumstance. An appropriate illustration of this is afforded by pellagra, in which, while diseased maize is the agent which morbidly disturbs the system, it is the sun's rays which light up the ery thema, the integumentary manifestation. Viewed in this way it is not so improbable that some as yet undiscovered dietetic error may sow the seed which eventually under the solar beams ripens into xeroderma pigmentosum or hydroa vacciniforme.

When we endeavour to accuse special articles "of food or drink of possessing this remote power of occasioning cutaneous disturbance, there are but few to which we can positively bring home the charge. Alcohol abused tends to produce a degree of over-ready penetrability of the tissues, shown on the one hand, so far as the integumentary system is concerned, by the clammy moist hand of the habitual toper; but it can also, on the other, occasion undue and permanent dilatation of the blood vessels of the face and give rise to rosacea and a coarse greasy skin. Since this does not supervene in the case of all who are prone to this form of indulgence we must in many instances invoke some exciting factor. Of these exposure to all weathers is certainly one, but confinement in 